\title{
EFFECTS OF LIGHT ON IN VITRO TUBERIZATION OF THE POTATO CULTIVAR DESIREE AND ITS RELATIVES
}

\author{
JUDIT DOBRÁNSZKI* \\ Research Centre of Debrecen University, Westsik V. u. 4-6, H-4400 Nyíregyháza, Hungary
}

(Received: January 25, 2000; accepted: April 17, 2000)

\begin{abstract}
Effects of different combinations of short days and dark treatment and different light intensities during the short days on in vitro tuberization of three potato cultivars were examined. Tuberization in Desiree, Cleopatra and Gracia was induced by short-day-treatment after 4 weeks culture under long days. To preserve natural endogenous hormonal balance of in vitro plantlets growth regulators were not added to the medium. The shorter the duration of short-days period the higher light intensity necessary for earlier tuber initiation. There was also a synchronizing effect of the high light intensity on tuber initiation but it depended on photoperiod-treatments and genotypes. The higher the light intensity during induction period the less favourable the effect of light applied after the induction period.
\end{abstract}

Keywords: Photoperiod - light intensity - tuber initiation and development - tuber number

\section{INTRODUCTION}

In vitro tuberization for propagation of disease-free potatoes and for conservation of germplasm of potatoes has been reported $[9,15,19]$.

Recently some researchers have studied the effects of environmental factors, such as light or temperature, on in vitro tuberization. These studies did not use growth regulators in order to avoid the potential effect(s) of the regulators on the developmental response of in vitro culture $[1,3,4,5,6,7,10,18]$.

This study was undertaken to examine tuberization of in vitro plantlets from a similar genetic origin but of different maturity groups under different light intensities applied with various photoperiodic treatments in order to improve in vitro tuberization. 


\section{MATERIALS AND METHODS}

\section{Plant material}

In vitro culture of Solanum tuberosum L. cvs. Cleopatra (early maturity), Gracia (mid-early maturity) and Desiree (mid-late maturity) were used. They are related genotypes, because Desiree was one of the parents of both Cleopatra and Gracia.

\section{Shoot culture}

Nodal cuttings of four-week-old in vitro plants served as explants for the experiments. Initial explants were placed in jars (Kilner jars, $400 \mathrm{ml}, 75 \mathrm{~mm} \times 85 \mathrm{~mm}$ ) covered with plastic caps, and each containing 30 nodal explants on $40 \mathrm{ml}$ Murashige and Skoog [13] medium supplemented with $0.8 \%$ agar and 3\% sucrose. Cultures were maintained for four weeks in a culture room at $24 / 15^{\circ} \mathrm{C}$ day/night temperature and $16 \mathrm{~h}$ photoperiod and $106 \mu \mathrm{mol} \mathrm{m}^{-2} \mathrm{~s}^{-1}$ light intensity. On average 27 fully developed plantlets (at least $4 \mathrm{~cm}$ long with large leaf surface and well-developed roots) per jar developed after the long-day-treatment of four weeks.

\section{Tuber induction treatment}

Tuber induction treatments were carried out after four weeks of long-day-treatments. This period was required for vigorous plantlet development in vitro [8, 17], which is an essential precondition for the perception of the environmental stimuli, such as light $[8,17]$. Tuberization was induced on the same medium with a layer of $8 \%$ sucrose solution poured onto the cultures $(5 \mathrm{ml}$ in each jar). Five different photoperiodic regimes (Table 1) were used giving different combinations of short days $(8 \mathrm{~h}$ illumination/day) and total darkness ( $0 \mathrm{~h}$ illumination/day).

Three different light intensities were applied during short-day-treatments: 106 $\mu \mathrm{mol} \mathrm{m} \mathrm{m}^{-2} \mathrm{~s}^{-1}$ (Li-0 treatment), $53 \mu \mathrm{mol} \mathrm{m} \mathrm{m}^{-2} \mathrm{~s}^{-1}$ (Li-1 treatment), $5.3 \mu \mathrm{mol} \mathrm{m}^{-2} \mathrm{~s}^{-1}$ (Li-2 treatment). Warm-white fluorescent tubes with the waveband between 400-700 $\mathrm{nm}$ were used as light source.

\section{Measurement and data analysis}

The time for tuber initiation in vitro was determined as the time of the appearance of the first microtuber in a jar. Tuber development was recorded by counting the number of tubers per jar every 2 weeks after tuber initiation and by observing the morphological type of the developing tubers. Tuber size and number of microtubers per jar from each treatment was evaluated at the end of each experiment (after 17 weeks). At least 10 replicates were analysed for each treatment. The statistical analysis of 
data for tuber initiation and number was made by analysis of variance or by other robust tests (Welch-, James-, Brown-Forsythe-tests) related to analysis of variance depending on the results of tests for standard deviations [2]. The standard deviations were analysed by Bartlett-, O'Brien- and Levene-tests [11]. Analyses were conducted with SPSS PC+4 software.

\section{RESULTS AND DISCUSSION}

\section{Tuber initiation}

The time for tuber initiation varied with the photoperiodic and light intensity treatments in each genotype (data presented in Fig. 1).

Darkness applied after high light intensity had an accelerating effect on the appearance of tubers. Fp-2 and Fp-3 treatments resulted in earlier tuber initiation in all examined cultivars compared to the Fp-1 treatment. The treatments with one week or less under short days (Fp-4 and $\mathrm{Fp}-5$ treatments) caused a further decrease in the number of days required to initiation in case of Grácia and Desiree. If the dark- and short-day-treatment was combined according to the demand of the given genotype, the dark treatment led to synchronization of tuber initiation. This synchronization effect of darkness was expressed by significant decrease of the standard deviation(s) of data in case of Desiree and Gracia in the Fp-2 and the Fp-3 treatments. The same effect of dark treatment was obtainable in the Fp-3 treatment in case of Cleopatra. However, the further reduction of the period of short day treatment applied before darkness caused the cessation of its synchronizing effect in all cultivars.

After medium light intensity (Li-1 treatment), the effect of darkness applied in the Fp-2-5 treatments varied according to genotype. A synchronizing effect of darkness on tuber formation in the Fp-2-4 treatments also occurred in Cleopatra and Gracia.

After low light intensity (Li-2 treatment) the dark treatment had both accelerating (Cleopatra, Gracia) and delaying (Desiree) effects on tuber initiation depending on genotype as listed. The synchronizing effect of this treatment was also observed in Cleopatra and Gracia.

It can be concluded that short-day-treatment applied after induction phase had a delaying effect on tuber initiation, while darkness applied after the induction phase accelerated and synchronized tuber initiation when high light intensity was applied before dark treatment. After lower light intensities the dark treatment had only synchronizing effect on tuber initiation. However, the dark-treatment was effective only when the short-day-treatment was long enough before exposure to dark. The required length of short-day-treatment was genotype-dependent.

The shorter the duration of short-days period the higher is light-intensity necessary during short days to induce earlier tuber initiation. There was also a noticeable synchronizing effect of the highest light intensity on tuber initiation depending on photoperiod-treatments and genotypes. 


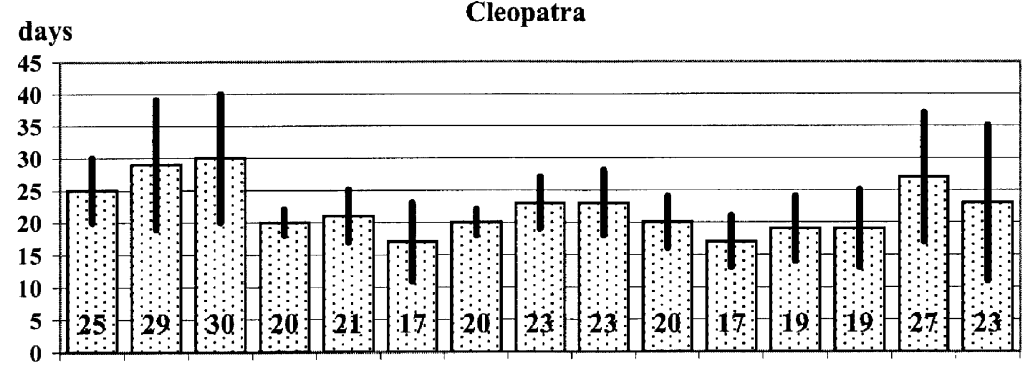

Fp-1, Fp-1, Fp-1, Fp-2, Fp-2, Fp-2, Fp-3, Fp-3, Fp-3, Fp-4, Fp-4, Fp-4, Fp-5, Fp-5, Fp-5,

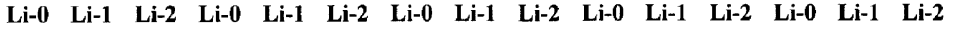

Light treatments

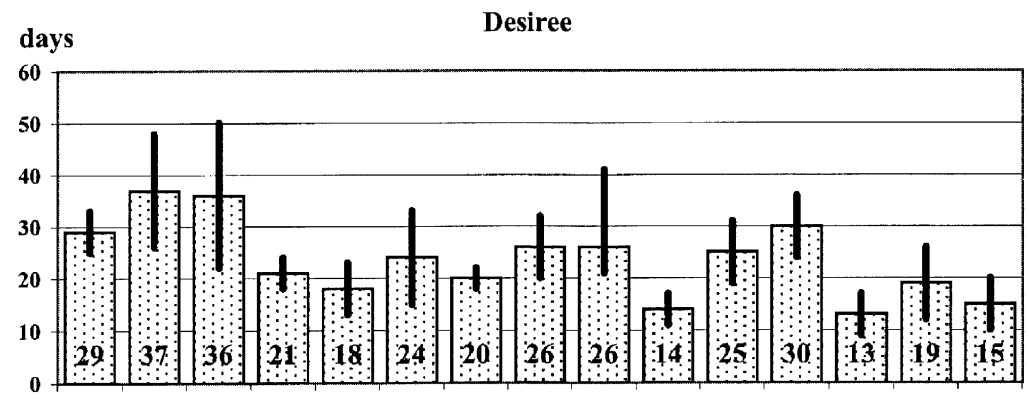

Fp-1, Fp-1, Fp-1, Fp-2, Fp-2, Fp-2, Fp-3, Fp-3, Fp-3, Fp-4, Fp-4, Fp-4, Fp-5, Fp-5, Fp-5,

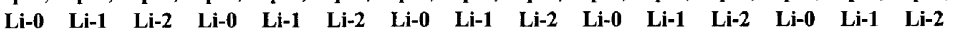

Light treatments

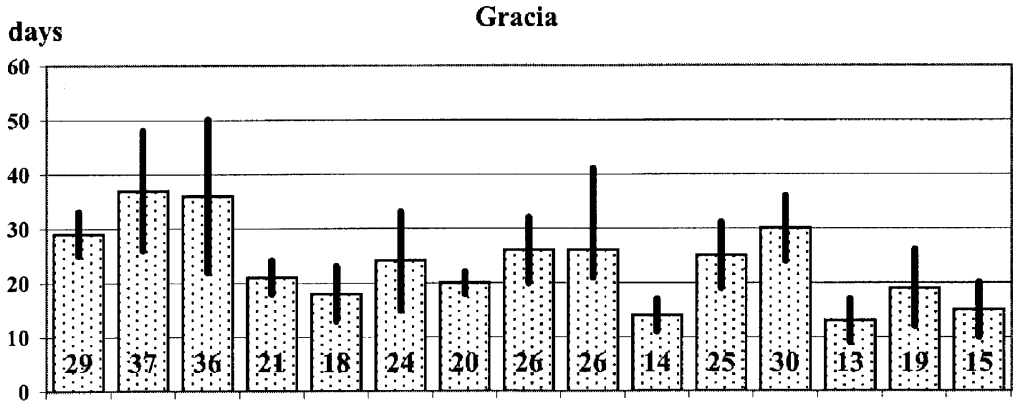

Fp-1, Fp-1, Fp-1, Fp-2, Fp-2, Fp-2, Fp-3, Fp-3, Fp-3, Fp-4, Fp-4, Fp-4, Fp-5, Fp-5, Fp-5,

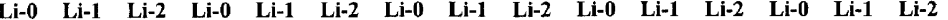

Light treatments

Fig. 1. Number of days required for appearance of the first tuber in each jar at the different light treatments (Fp: photoperiod-treatments, Li: light-intensity treatments applied during short days) 


\section{Cleopatra}

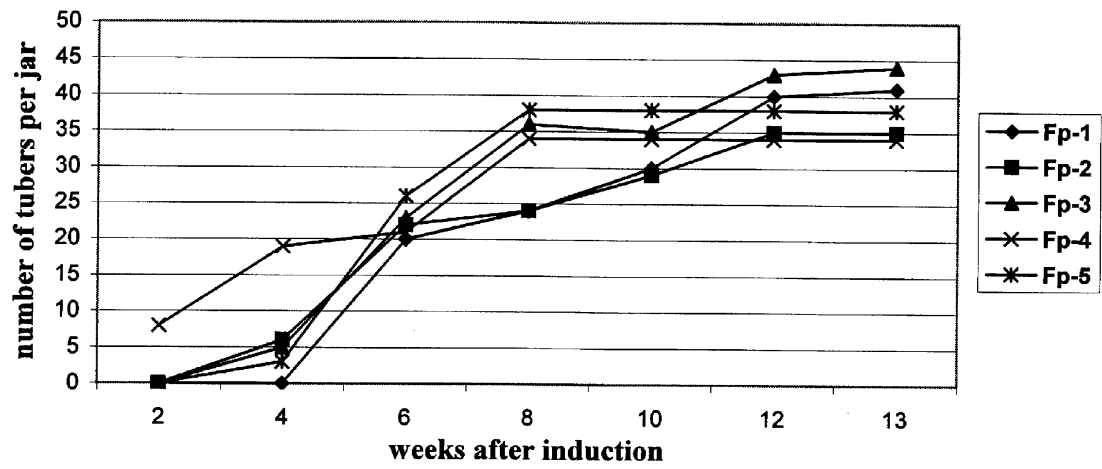

Desiree

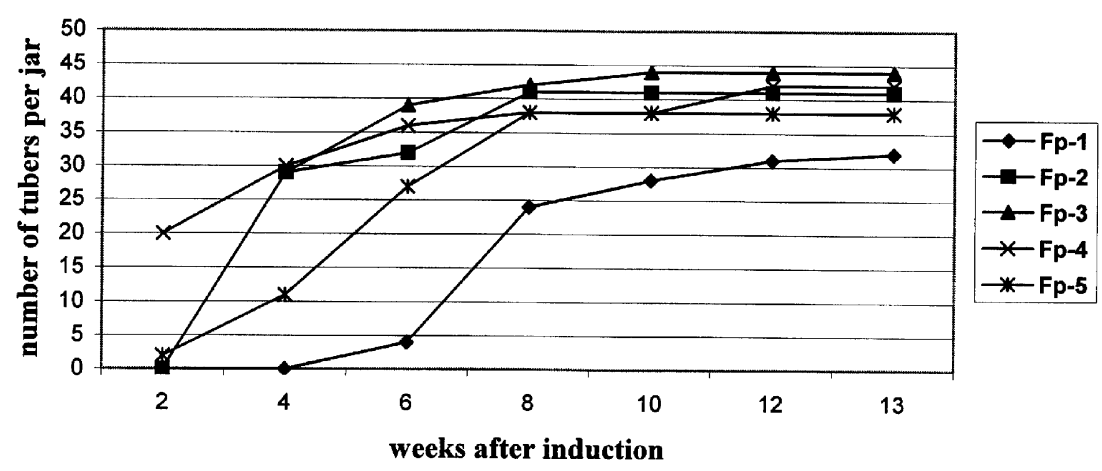

Gracia

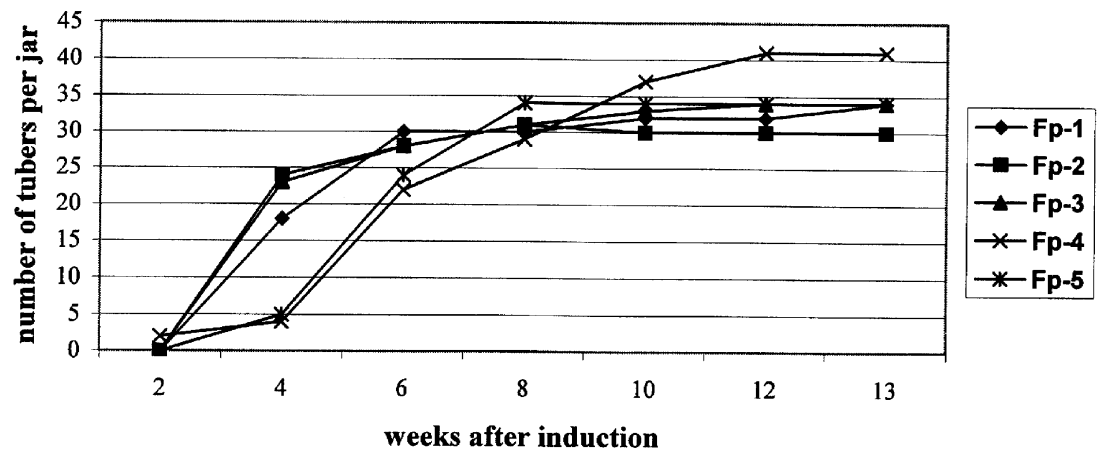

Fig. 2. Development of microtubers after induction at high light-intensity treatment 


\section{Cleopatra}

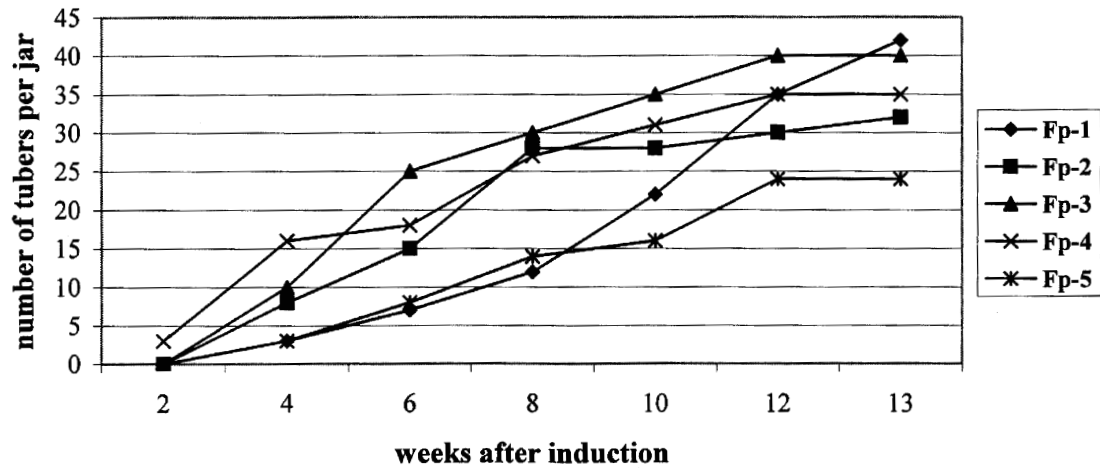

\section{Desiree}

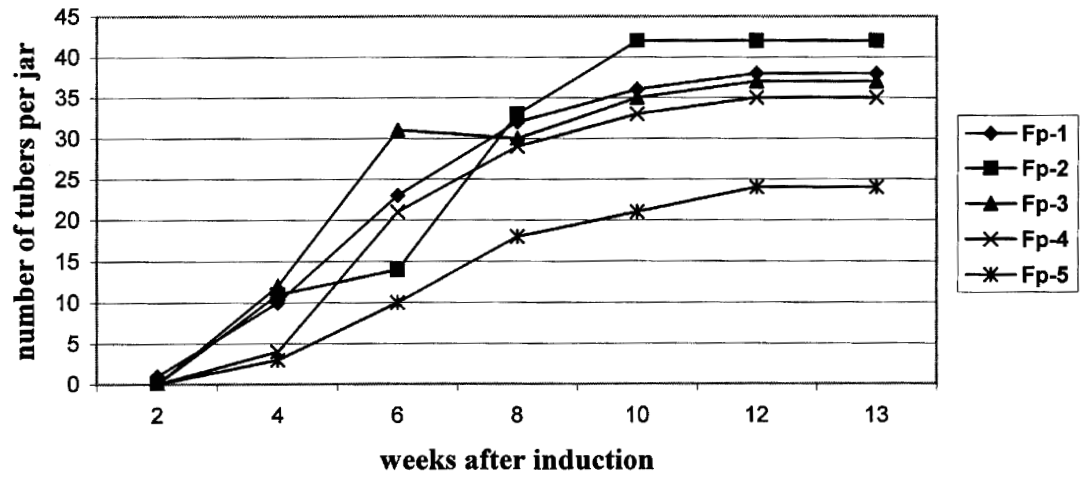

Gracia

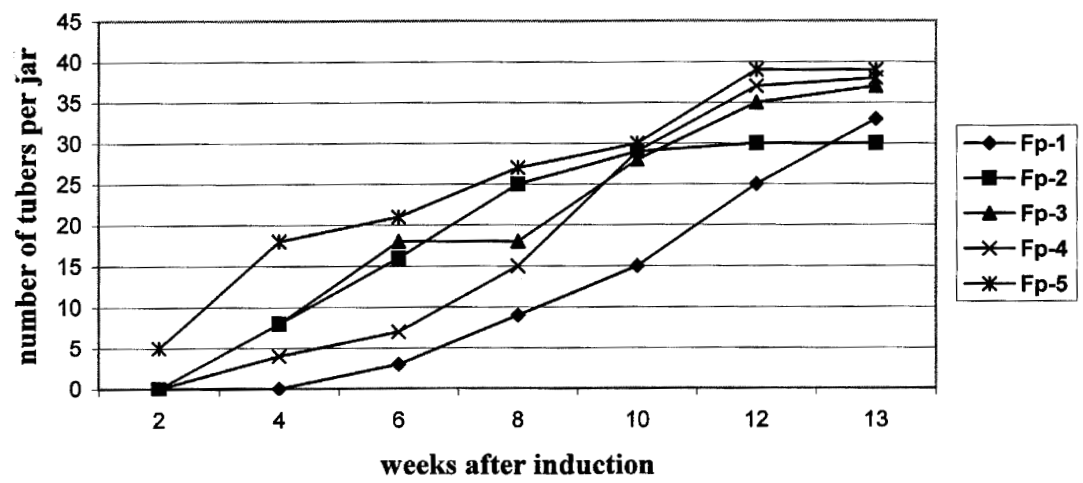

Fig. 3. Development of microtubers after induction at medium light-intensity treatment 


\section{Cleopatra}

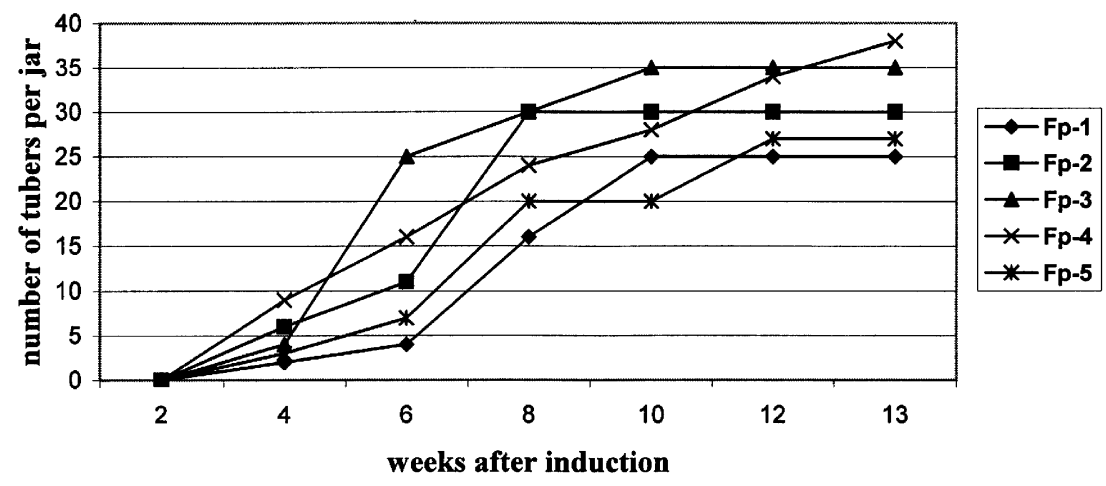

Desiree

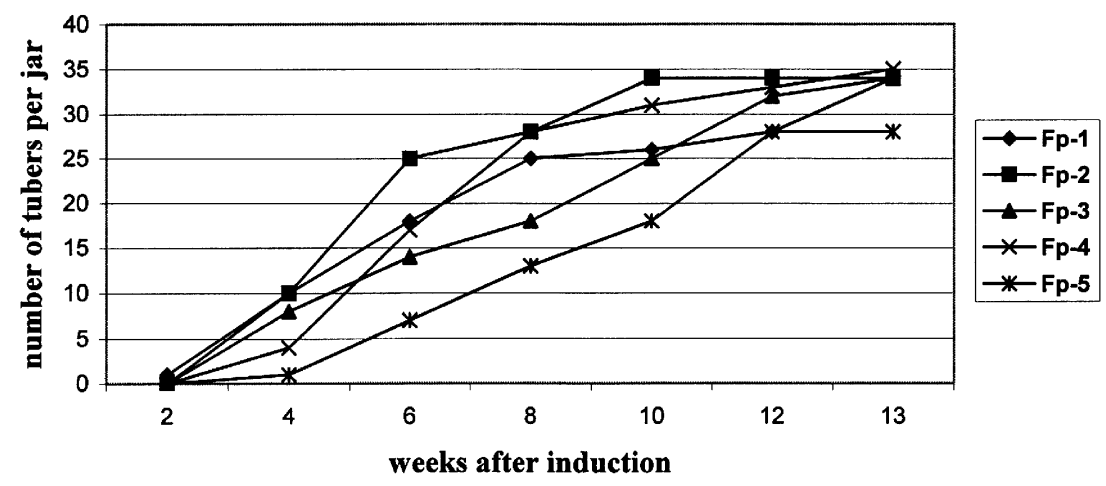

\section{Gracia}

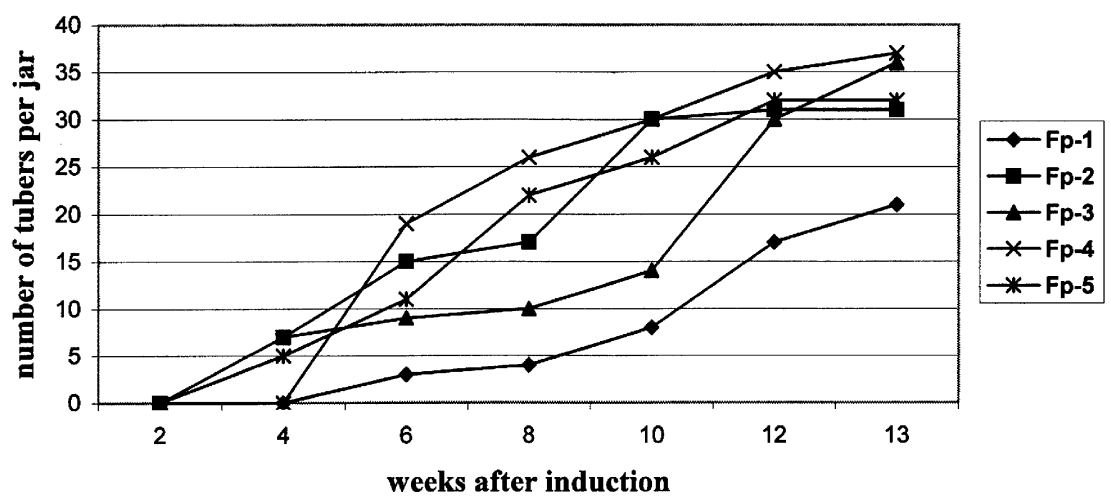

Fig. 4. Development of microtubers after induction at low light-intensity treatment 
MANOVA and related methods (see above) proved that both the main effects and 2-way interactions (Fp-Li, Fp-Clones, Li-Clones) and also the 3-way interaction ( $\mathrm{Fp}$ Li-Clones) were significant $(\mathrm{P}<0.01)$.

These results indicate that an adequate quantity of light illumination is without doubt necessary to induce tuberization but the further light effects can be unfavourable.

\section{Tuber development}

After high light-intensity the dark treatments led to a significant increase in the number of tubers per jar, which can be seen from the second week after induction in the Fp-2 and Fp-3 treatments and from the first week and from the third day after induction in the Fp-4 and Fp-5 treatments, respectively. Accordingly, in these treatments 2 weeks (Fp-2, Fp-3) or 1 week (Fp-4) or 3 days (Fp-5) short-day-treatments were applied before cultures were exposed to dark.

The number of tubers increased markedly during the 3rd and 4th weeks when the cultures were kept in the dark (Fp-2, Fp-3 treatments) compared to those cultures, which were kept in short days (Fp-1). However, replacing of cultures from dark to short days (Fp-2 treatment) caused a temporary, but obvious inhibition in the formation of new tubers compared to those cultures remaining in dark (Fp-3 treatment) (Fig. 2).

At lower light-intensities the increase in tuber number was faster as compared to treatment in the highest light-intensity but only in case of Fp-1 treatment. This effect of the lower light-intensities was just the contrary in the other Fp-treatments. In the Fp-4 and Fp-5 treatments tuber initiation was delayed and the final tuber number was

Table 1

The photoperiod-treatments applied after the four week culture period under long days

\begin{tabular}{lccc}
\hline \multirow{2}{*}{ Treatments } & \multicolumn{3}{c}{ Weeks $^{\mathrm{a}}$} \\
\cline { 2 - 4 } & SD (8 h) & D (0 h) & SD (8 h) \\
\hline Fp-1 & 13 & - & - \\
Fp-2 & 2 & 2 & 9 \\
Fp-3 & 2 & 11 & - \\
Fp-4 & 1 & 12 & - \\
Fp-5 & $0+3$ days & $11+4$ days & - \\
\hline
\end{tabular}

a SD: short days ( $8 \mathrm{~h}$ daily illumination), D: darkness ( 0 h daily illumination).

${ }^{\mathrm{b}}$ Cultures were kept for 3 days at $8 \mathrm{~h}$ photoperiod prior to exposure to total darkness ( $0 \mathrm{~h}$ daily illumination). 
lower when the highest light-intensity was applied during the short days. However, the tuberization responses of different genotypes to the different light-intensities were different (Figs 3-4).

The morphology of developing tubers (sessile or non-sessile type) was determined according to McGrady et al. [12]. The earlier application of dark treatment resulted in increasing percentages of sessile tubers in comparison with non-sessile ones, which can indicate stronger tuberization stimulus.

When the development of tubers occurred mainly under light conditions (Fp-1 and Fp-2 treatments), the tubers formed either in the medium or developed at the end of long stolons directly under the plastic cap of the culture jars. Microtubers developed within the medium had prominent lenticels, larger diameter $(0.7$ to $1.8 \mathrm{~cm})$ and their epidermis often split open, which prevented their further use. This effect of light was observable mainly in case of Gracia. The colour of these tubers varied from green to blackish green, which was probably due to their development under light, moreover their shapes was true-to-type.

Microtubers produced in the Fp-3-5 treatments were positioned high above the surface of medium and were round. The colours of tuber skin were true-to-type, yellow or red depending on genotypes. However, their diameter was smaller than that of tubers produced under light conditions. The similar morphological characteristics of microtubers developed under different light conditions were observed by Slimmon et al. [16] and Novak \& Asiedu [14].

\section{Tuber number}

Both the final number of developed tubers and the number of tubers with $2 \mathrm{~mm}$ or larger than $2 \mathrm{~mm}$ in diameters were analysed by MANOVA and related methods. Table 2 includes the average number of microtubers with 2 or larger than $2 \mathrm{~mm}$ in diameter per jar after 17 weeks. The analyses proved correlations between the treatments and between the treatments and clones and also the 3-way correlantions was significant $(\mathrm{P}<0.01)$.

If cultures were exposed to light during all the experiments (Fp-1 treatment) the medium light-intensity ( $\mathrm{Li}-1$ treatment, $53 \mu \mathrm{mol} \mathrm{m}^{-2} \mathrm{~s}^{-1}$ ) was as favourable as the highest light-intensity. With the extension of darkness, the highest light-intensity was more favourable for producing more in vitro tubers.

In general, the most favourable conditions to maximize the number of tubers with 2 or larger than $2 \mathrm{~mm}$ in diameter were the Fp-3 or Fp-4 treatments and high lightintensity applied under short days. Although the tuber number was not significantly different in the Fp-1 and Fp-2 treatments compared to those developed in the Fp-3 or Fp-4 treatments in Cleopatra and Desiree, the loss of tuber number during storage was significantly larger for tubers produced by Fp-1 and Fp-2 treatments (data not presented).

The tuber number always reached 1.00 tuber per plantlet (1.26 to 1.33 depending on cultivars) in the best treatments if we counted only the tubers with 2 or larger than 
$2 \mathrm{~mm}$ in diameters. The best treatment means the rational in vitro application of light as an environmental factor controlling tuberization process of potato in vivo. These results are better than those which were obtained by using growth regulators to induction of in vitro tubers $[16,19,20]$.

Table 2

Average number of in vitro tubers with diameter larger than $2 \mathrm{~mm}$ in each jar after 17 weeks $^{\mathrm{a}}$

\begin{tabular}{|c|c|c|c|c|c|}
\hline Treatment & Fp-1 & Fp-2 & Fp-3 & Fp-4 & Fp-5 \\
\hline \multicolumn{6}{|l|}{$\begin{array}{l}\text { Light-intensity } \\
\left(\mu \mathrm{mol} \mathrm{m} \mathrm{m}^{-2} \mathrm{~s}^{-1}\right)\end{array}$} \\
\hline \multicolumn{6}{|c|}{ Desiree } \\
\hline 106 & $34 \mathrm{a}, \mathrm{A}$ & $36 \mathrm{a}, \mathrm{A}$ & $35 \mathrm{a}, \mathrm{B}$ & $35 \mathrm{a}, \mathrm{AB}$ & $34 \mathrm{a}, \mathrm{B}$ \\
\hline 53 & $35 \mathrm{~b}, \mathrm{~A}$ & $32 \mathrm{~b}, \mathrm{~A}$ & 29 b,A & $30 \mathrm{~b}, \mathrm{~A}$ & $18 \mathrm{a}, \mathrm{A}$ \\
\hline 5.3 & $29 \mathrm{~b}, \mathrm{~A}$ & $31 \mathrm{~b}, \mathrm{~A}$ & 30 b,A & $32 \mathrm{~b}, \mathrm{~A}$ & $20 \mathrm{a}, \mathrm{A}$ \\
\hline \multicolumn{6}{|c|}{ Cleopatra } \\
\hline 106 & $32 \mathrm{a}, \mathrm{B}$ & 31 a,B & 34 a,B & $34 \mathrm{a}, \mathrm{A}$ & $32 \mathrm{a}, \mathrm{C}$ \\
\hline 53 & $31 \mathrm{~b}, \mathrm{~B}$ & $25 \mathrm{ab}, \mathrm{AB}$ & $29 \mathrm{~b}, \mathrm{~A}$ & $30 \mathrm{~b}, \mathrm{~A}$ & 19 a,B \\
\hline 5.3 & 19 a,A & $23 \mathrm{a}, \mathrm{A}$ & 27 b,A & $32 \mathrm{~b}, \mathrm{~A}$ & $14 \mathrm{a}, \mathrm{A}$ \\
\hline \multicolumn{6}{|c|}{ Gracia } \\
\hline 106 & $23 \mathrm{a}, \mathrm{B}$ & $28 \mathrm{a}, \mathrm{A}$ & $33 \mathrm{ab}, \mathrm{A}$ & $35 \mathrm{~b}, \mathrm{~A}$ & $30 \mathrm{ab}, \mathrm{A}$ \\
\hline 53 & $21 \mathrm{a}, \mathrm{B}$ & $27 \mathrm{a}, \mathrm{A}$ & $32 \mathrm{ab}, \mathrm{A}$ & $34 \mathrm{~b}, \mathrm{~A}$ & $31 \mathrm{a}, \mathrm{A}$ \\
\hline 5.3 & $13 \mathrm{a}, \mathrm{A}$ & $23 \mathrm{~b}, \mathrm{~A}$ & 28 b,A & $31 \mathrm{~b}, \mathrm{~A}$ & $33 \mathrm{~b}, \mathrm{~A}$ \\
\hline
\end{tabular}

${ }^{a}$ Means within the rows followed by the same small letter are not significantly different $(P=0.01)$ and means within columns followed by the same capital letter are not significantly different $(\mathrm{P}=0.01)$ in each genotype.

\section{ACKNOWLEDGEMENT}

The author wishes to thank Dr. J. Szalai for his critical reading of the manuscript.

\section{REFERENCES}

1. Akita, M., Takayama, S. (1994) Stimulation of potato (Solanum tuberosum L.) tuberization by semicontinuous liquid medium surface level control. Plant Cell Reports 13, 184-187.

2. Brown, M. B., Forsythe, A. B. (1974) Robust tests for the equality of variances. J. Am. Statistical Ass. 69, 364-367.

3. Charles, G., Rossignol, L., Rossignol, M. (1992) Environmental effects on potato plants in vitro. J. Plant Physiol. 139, 708-713.

4. Charles, G., Rossignol, L., Rossignol, M. (1993) A synchronous model perfecting for fundamental studies on the tuberization process. J. Plant Physiol. 142, 474-479.

5. Dobránszki, J. (1996) Effects of dark treatment on tuber initiation and development of induced potato plantlets cultured in vitro. Acta Agronom. Hung. 44, 377-386. 
6. Dobránszki, J., Mándi, M. (1993) Induction of in vitro tuberization by short day period and dark treatment of potato plants in vitro on medium free of growth regulators. Acta Biol. Hung. 44, 411-420.

7. Garner, N., Blake, J. (1989) The induction and development of potato microtubers in vitro on media free of growth regulating substances. Ann. Botany 63, 663-674.

8. Hammes, P. S., Beyers, E. A. (1973) Localization of the photoperiodic perception in potatoes. Potato Research 16, 68-72.

9. Hussey, G., Stacy, N. J. (1981) In vitro propagation of potato (Solanum tuberosum L.). Ann. Botany $48,787-796$

10. Hussey, G., Stacy, N. J. (1984) Factors affecting the formation of in vitro tubers of potato (Solanum tuberosum L.). Ann. Botany 53, 565-578.

11. Levene, H. (1960) Robust tests for the equality of variances. In: Olkin, I., Ghurye, S. G., Hoeffding, W., Madow, W. G., Mann, H. B. (eds) Contributions to probability and statistics. Stanford University Press. Palo Alto.

12. McGrady, J. J., Struik, P. C., Ewing, E. E. (1986) Effects of exogenous application of cytokinin on the development of potato (Solanum tuberosum L.) cuttings. Potato Res. 29, 191-205.

13. Murashige, T., Skoog, F. (1962) A revised medium for rapid growth and bioassays with tobacco tissue cultures. Physiol. Plant. 15, 473-497.

14. Novak, J., Asiedu, S. K. (1992) Gelling agent and light effects on in vitro tuberization of potato cultivars. Am. Potato J. 69, 461-470.

15. Seabrook, J. E. A., Coleman, S., Levy, D. (1993) Effect of photoperiod on in vitro tuberization of potato (Solanum tuberosum L.). Plant Cell, Tissue and Organ Culture 34, 43-51.

16. Slimmon, T., Souza Machado, V., Coffin, R. (1989) The effect of light on in vitro microtuberization of potato cultivars. Am. Potato J. 66, 843-848.

17. Smith, H. (1982) Light quality, photoperception and plant strategy. Annu. Rev. Plant Physiol. 33, 481-518.

18. Thieme, R. (1988/89) An in vitro cultivar collection: microtuberization and storage of microtubers. FAO/IBPGR Plant Genetic Resources Newsletter, pp. 17-19.

19. Tovar, P., Estrada, R., Schilde-Rentschler, L., Dodds, J. H. (1985) Induction and use of in vitro potato tubers. CIP Circular 13, 1-5.

20. Wang, P. J., Hu, C. Y. (1982) In vitro mass tuberization and virus-free seed-potato production in Taiwan. Am. Potato J. 59, 33-39. 
